\title{
Geschichten zu Able Archer
}

\section{Alexander Kluge}

\section{(2) OpenEdition}

\section{Journals}

Édition électronique

URL : http://journals.openedition.org/ceg/1069

DOI : 10.4000/ceg.1069

ISSN : 2605-8359

\section{Éditeur}

Presses Universitaires de Provence

\section{Édition imprimée}

Date de publication : 18 décembre 2015

Pagination : 27-31

ISBN : 979-1-03200-020-5

ISSN : 0751-4239

\section{Référence électronique}

Alexander Kluge, «Geschichten zu Able Archer », Cahiers d'Études Germaniques [Online], 69 | 2015, Online erschienen am: 17 Dezember 2017, abgerufen am 25 November 2020. URL : http://

journals.openedition.org/ceg/1069; DOI : https://doi.org/10.4000/ceg.1069 


\section{Geschichten zu Able Archer}

Alexander KLUGE

\section{Der gefährlichste Moment im kalten Krieg}

Es war vielleicht etwas übermütig, daß meine Frau und ich im September 1983 unsere erst vor 21 Wochen geborene Tochter ins Fahrzeug packten und uns zum Lido von Venedig in Bewegung setzten. Mein Film DIE MACHT DER GEFÜHLE war fertiggestellt, und ich zeigte ihn in der Sala Volpi auf den Filmfestspielen.

Von der Adria drängten gegen Abend Wolken mit einem gelben Unterrand zum Lido hin. Man hätte sie für giftig halten können. Tatsächlich ging von ihnen keine Gefahr aus. Die Färbung war verursacht durch das Licht, das vom Wasser her sich in überraschender Weise in ihnen spiegelte. Dieser Sommer, nahm ich an, gehörte zu meinen Glückszeiten.

\section{Das legendäre Stabsrahmenmanöver Able Archer, an dem 33000 Leute mitwirkten}

Im April 1945 war ich noch aktiv. In einem Jahr werde ich pensioniert sein. Die Karten, in denen die Annahmen für die Stabsrahmenübung Able Archer niedergelegt sind, tragen französische Ortsnamen; Olomouc für Olmütz, Ratisbonne für Regensburg. Die Nachrichtenmittel sind britischen Ursprungs. Unsere Stäbe sind zusammengesetzt aus kanadischem, französischem, englischem und USPersonal. Obwohl wir einheitlich in englischer Sprache kommunizieren, sind die Sprachbarrieren unüberwindlich, da ja die professionelle Erfahrung eine Sprache für sich bildet. Ich weiß nicht, ob es für mich schwieriger ist, mich mit einem Kameraden, der in West Point oder Annapolis ausgebildet wurde (großer Unterschied!), zu verständigen oder ob es aufwendiger ist, mich mit den jüngeren Kameraden in unserer Bundeswehr auszutauschen, die den Krieg nicht kennen.

Als damals junger Generalstäbler in der Ersten Panzerarmee auf dem Rückzug in den letzten Tagen des April pflügten wir in drei Kolonnen nebeneinander über Mährens Chausseen ins Böhmische und suchten dort in die Greifweite der USPanzer des Generals Patton zu gelangen: Gewinn eines passenden Geländes, in dem wir kapitulieren konnten. Genau auf dieser Rückzugslinie, die ich ja noch kenne, bewegten sich nach der Annahme des Manövers zwei Stoßarmeen des Ostblocks in Richtung Westen. Sie haben den dünnen Schleier von Nato-Truppen durchstoßen 
und zwei, drei der Übungsplätze überrollt, auf denen symbolisch Verteidiger stehen.

Wir hatten in diesem Manöver einen guten Überblick, weil die Stäbe, die geteilt in die Parteien Blau (Westen) und Rot (Osten) den Krisenfall übten, in Wirklichkeit aber, insofern es sich um eine Rahmenübung handelte, in ihren Stabsgebäuden verblieben, eine Situation, die es im Krieg weder jetzt im November 1983 noch einst 1945 so gegeben hat. Wir sahen dann in den nächsten Stunden den Angriff im Norden aus Mecklenburg in Richtung der Weser und erwarteten, daß über die Kommunikationsnetze, über die uns die Lagenachrichten erreichten, der Vormarsch der Hauptmacht von Rot (entsprechend den Streitkräften der Westgruppe der Roten Armee in der Wirklichkeit) gemeldet werden würde. Der Gegner war im Manöverplan nur unzureichend verfremdet.

Die Schiedsrichter ließen zu, daß wir uns durch Telefonate und Funk mit der Gegenpartei verständigten. Wir mußten auch nur in die Kantine unseres Dienstgebäudes gehen, wenn wir den Gegner Rot etwas fragen wollten. Das erleichterte es, die Entscheidungsprozesse zu einigen Kernfragen vorwärts zu treiben, die nicht wir, sondern die Krisenstäbe der in der Nato vereinigten Regierungen zu entscheiden hatten. Das Studium dieser Schwellen, in denen eine solche Krise eskaliert (mit dem Vorstoß der zentralen Panzerarmeen, nachdem Rot die Luftherrschaft an sich gerissen hat, in Richtung Fulda und Göttingen), war das Ziel der Übung. Man mußte sofort zu Beginn des Angriffs von Rot taktische Atomwaffen einsetzen, andernfalls konnte man gleich bis zur Atlantikküste zurückgehen und versuchen, gewisse Reste an Truppen einzuschiffen. Das probten wir mit Fähnchen auf Karten.

Meine Aufgabe lag in der geheimdienstlichen Abschirmung von Blau gegen Agenten von Rot. Auch sollten die mir unterstehenden Aufklärungsnetze die Bewegungen von Rot vorhersagen. Das war in einer Rahmenübung, also als reine Theorie, nichts Praktisches und nichts Durchführbares. So hatte ich viel Zeit zum Vergleichen, zum Erinnern an das, was ich vom Kriege wußte, und zur Herstellung einer Skizze, was man, wäre es kein Manöver, im Ernstfall tatsächlich unternehmen müßte als geheimdienstlicher Verantwortlicher. Es wäre für mich auch jetzt interessant gewesen, nicht zu studieren, was die fiktive Partei Rot plante, sondern was die durch ihre Späher ja in unseren Reihen mit Gewißheit präsenten und hochinformierten Dienste der realen Gegenseite, also die ausgezeichneten Mitarbeiter der russischen, tschechoslowakischen, ungarischen, polnischen Dienste sowie die sicher in der Nato eingeschleusten Aufklärer der DDR von dem Manöver hielten. Nichts verrät besser die Planungen des Gegners als die Ansatzpunkte seiner Spione. Kenne ich die Stellen, für die er sich bei uns interessiert, errate ich, was er plant. Deshalb enttarnen wir auch gegnerische Agenten, die wir entdecken, nie ohne Not. Vielmehr studieren wir ihre verräterischen Spuren. Oft bewege ich mich mit wachen Augen durch die Kasinos meiner Dienststelle und anderer Nato-Quartiere. Häufig entdecke ich dann Personen, die ich für Spione des Gegners halte. Und oft schon ergab sich ein tastendes Gespräch, das für beide Seiten viel Information enthielt und mehr erbrachte als die Querkontakte zwischen den Manöverstäben, die etwa dem gegenseitigen Abschreiben in der Schulpause bei Schülern entsprechen. 


\section{Ich, genannt TOPAS}

Ich, der heute in seiner Personalakte, die nach der Wende die Augen des Gegners erreichte (aus Häckseln der Schreddermaschinen, die nicht genug taugten, von Experten zusammengesetzt), seinen Tarnnamen TOPAS mit Stolz liest, auch wenn ich für diese Aufdeckung mit langer Haft büßen mußte, rechne es mir hoch an, daß es meine Meldung im November 1983 war, die ein grobes Mißverständnis von unserer Seite, das sich auf das Manöver Able Archer bezog, noch rechtzeitig ausräumte. Wie eine solche Meldung von meinem Arbeitsplatz in herausragender Position inmitten der Nato in die Moskauer Zentrale gelangte, das unterliegt noch immer meiner Verschwiegenheit. Wichtig war, daß die Kollegen in der Zentrale mir glaubten. Sie taten das, weil sie wußten, daß alle Planungen der Nato, die sich auf ein Angriffspotential hätten beziehen können, über meinen Schreibtisch gingen. Ich ahnte die Aufregung, die bei den Analysten in Moskau, die mich führten, sich angesammelt hatte. Die Ereignisse des Jahres waren tatsächlich unübersichtlich. Insgesamt, so mein Urteil, hatte der Westen (also „wir“ in der Nato) zuwenig Information über das, was die Gegenseite bewegte. Und der Warschauer Pakt (also wiederum von mir aus gesehen ,wir“) zuviel Information über das, was im Westen geplant, geredet, entworfen, wieder verworfen und angezettelt wurde. Das Zuwenig war genauso gefährlich wie das Zuviel. Rückblickend schlage ich vor (aber ich werde wohl nie mehr als der Experte, der ich bin, von irgendeiner Großmacht befragt werden), die Dach- und Kontrollorganisationen sollten das Maß an Spionagedaten auf seine gleichgewichtige Verteilung hin überprüfen und die Erlaubnis erhalten, notfalls aus eigenem Ermessen Informationen nachzufüttern oder zu vermindern. Die Sicherheit der Welt hängt von solchem Gleichgewicht ab.

\section{Wie aus einem Mißverständnis ein Fiasko hätte werden können}

Eines der großen Frankfurter Hotels besitzt einen Allzweck-Tagungsraum. Hier findet die Konferenz statt. Für das Podium ist der eingeladene Russe, Stanislaw Petrow, gar nicht erst vorgesehen. Dort sitzen Wichtigtuer, bemüht, ihre Planstellen, ihre Anträge auf Drittmittel, ihre jüngst publizierten Artikel und Bücher durch Referate und „kritische Zwischenrufe“ zu untermauern. Die Einladung von Petrow, der inzwischen pensioniert ist, geht auf den Hinweis eines Hamburger Instituts für Sicherheitspolitik zurück, das als informiert gilt. Den Vormittag über hat er in der „Schirn“ eine Ausstellung über Propagandakunst der Stalinzeit besichtigt. Das hat ihn emotional gefesselt. Dann ist er, immer den Schaufenstern entlang, von den hochpreisigen Läden in der Goethestraße über den Roßmarkt und die Hauptwache hinweg zur Zeil vorgedrungen und hat hier noch vor dem Zoologischen Garten eine Reihe kleiner Läden entdeckt. Hier hat er eine Tragetasche gekauft, in die er Mitbringsel packen will, wenn er in sein Vaterland zurückfährt. Ihm sind Spesen versprochen. Sie liegen höher als seine Ausgaben. 
Ich treffe diesen Mann, weil die Zeitung, für die ich arbeite, viel Raum für tatsächlich relevante und überraschende Information hat, aber gar keinen Platz aufweist für die Wiedergabe bloßer Konferenztexte. Mir scheint Petrow einer der wenigen im Tagungsraum zu sein, der über eigene Erfahrung verfügt bezüglich der zeitgeschichtlichen Periode, um die es auf dieser Historikerkonferenz geht.

- Sprechen wir über den 26. September 1983?

- Danach fragen alle. Ich warte darauf, daß einer sich nach einem gewöhnlichen Arbeitstag, nach den Grundsätzen unserer Arbeit erkundigt. Ein einzelner Tag, an dem etwas Besonderes geschieht oder hätte geschehen können, ist nur auf dem Hintergrund aller Tage, also des Durchschnitts und des Kollektivs, informativ.

Ich sah, daß mein Gegenüber verspannt war. Wir verständigten uns über einen Dolmetscher, das war er nicht gewohnt. Und die Rede und Gegenrede kam nicht in Fluß.

Auch merkte ich, daß ich nicht feststellend, sondern fragend reden mußte.

- Zu welcher Zeit war es? War es gegen Mitternacht Moskauer Zeit?

- Etwa. Die Schicht beginnt um 19 Uhr.

- Ihre Computer schrillten? Sie geben Alarm?

- Sie schrillen nicht. Daß etwas nicht in Ordnung ist, sozusagen Alarmstufe, zeigen stumm die Monitore.

- Was zeigten die?

- Grüne Zacken. Das bedeutet „Flugkörper über dem Nordpol““.

- Wie viele?

- Fünf.

- Könnten das auch Flugzeuge sein statt Raketen?

- Wie sollen Flugzeuge dort hinkommen?

- Auf wie vielen ihrer Computer waren solche Zacken zu sehen?

- Auf allen 26. Die Geräte waren noch nicht lange in Betrieb. Wir hielten sie nicht für zuverlässig.

- Waren Sie erschrocken?

- Wir überprüften nicht die Computer, sondern die Originalinformation. Auf den Schreibern der Satelliten im Orbit.

- Die konnten Sie sehen?

- Man muß sie aufrufen.

- Die Beobachtung wurde bestätigt?

- Richtig. Einer der sieben Satelliten, sah die Objekte, die in der Nähe des Nordpols sich in Richtung Moskau zu bewegen schienen. Ein zweiter überflog die Raketenrampen in Ohio. Wir konnten also die beiden Daten miteinander in Verbindung setzen.

- Trotzdem gaben sie keinen Alarm?

- Man muß nicht gleich laut werden. Wir waren unruhig.

- Bezweifelten Sie die Signale auf ihren Monitoren?

- Es gibt Fälle, in denen die Strahlen der Abendsonne in einem bestimmten Winkel zu einer Wolkenformation ein Signal ergeben, das einer beobachteten Rakete 
entspricht. Die Zacken unterliegen der Deutung.

- Und was hielt Sie von einer Meldung nach oben ab?

- Die Zahl 5. Die Flugbahn von fünf Objekten in Richtung Moskau entsprach nicht dem uns bekannten und eingeübten Kriegsbild.

- Dem Kriegsbild hätte ein Massenstart entsprochen?

- Nun ist ein Kriegsbild eine Hypothese, keine feststehende Größe. Es setzt sich zusammen aus Wahrscheinlichkeiten, von denen es keine einzelne tatsächlich gibt. Der Anfang eines Krieges kann auch aus lauter Unwahrscheinlichkeiten zusammengesetzt sein.

- Was Sie generell befürchteten, war ein sogenannter „Enthauptungsschlag“? Kann so etwas mit fünf Flugkörpern gelingen?

- Gelingen nicht. Aber es kann versucht werden.

- Warum zögerten Sie, Ihre Vorgesetzten und das Politbüro zu benachrichtigen?

- Wir hielten die Vorgesetzten für beunruhigt genug. Die Mitteilung der Computer und der Beobachter im Orbit schien uns nicht eindeutig zu sein.

- Was unternahmen Ihre Mitarbeiter?

- Wir schalteten die Computer ab und wieder ein. Wir resetteten alle Geräte.

- Eine große Verantwortung lastete auf Ihnen!

- Ich dachte an meinen Ausbilder W. E. Antonow. Er beschrieb uns (in einem früheren Fall) die Zentrale, an die wir melden sollten, als ein „nervöses Instrument“. Man muß es, sagte er, ebenso fürchten wie die Zeichen, die vom Gegner zu uns gelangen.

- Zögern sollten Sie aber auch nicht.

- Rasches Handeln ist Pflicht.

- Aufgrund der Abwägung?

- Welcher Abwägung? $\mathrm{Ob}$ es für das Vaterland gefährlicher ist, in das politische Zentrum, ein Hornissennest, hineinzustören oder ob es gefährlicher ist, zu warten, ob sich die Flugkörper auf den Monitoren weiterbewegen? Alles war ein Experiment.

- Wie lang ging das vor sich hin?

- Eine gute Stunde. In der Nacht nochmals Alarm? Wir hatten dann aber schon die Erfahrung, daß die zuerst entdeckten Flugkörper von den Bildschirmen wieder verschwunden waren.

- Eine bis dahin unbekannte Situation?

- Eine übersichtliche.

- Wurden Sie belobigt oder bestraft?

- Weder noch.

Ich erkundete mich bei einem der Mitarbeiter des Hamburger Instituts für Sicherheitspolitik, welchen Vorteil eine Partei durch einen Erstschlag, den sie auslöst, gegenüber der anderen Supermacht hat, die darauf nicht vorbereitet ist. Das konnte er nicht angeben. Ich fragte Petrow dasselbe. Wer zuerst schlägt, lebt länger, antwortete er. Wieviel länger? Petrow: 20 bis 30 Minuten. Dann erfolgt der Gegenschlag. Man braucht eine gewisse Ruhe im entscheidenden Moment, schloß Petrow das Gespräch. 